\title{
Satisfação e insatisfação no trabalho de profissionais em hospital universitário
}

\author{
Satisfaction and dissatisfaction in the work of professionals at a \\ university hospital
}

Magda Duarte dos Anjos Scherer, $\mathbf{1}^{\mathbf{2}}$, Jacks Soratto ${ }^{\mathbf{3}}$, Letícia de Lima Trindade ${ }^{\mathbf{4}, \mathbf{5}}$, Denise Elvira

Pires de Pires ${ }^{6}$, Lusmair Martins de Brito ${ }^{1}$

DOI: 10.1590/0103-1104202113004

\begin{abstract}
RESUMO Estudo descritivo de abordagem qualitativa com objetivo de identificar aspectos geradores de satisfação e insatisfação no trabalho de profissionais de saúde de um hospital universitário. Participaram do estudo 52 profissionais da clínica cirúrgica e do serviço de emergência. A coleta de dados foi realizada por meio de entrevista individual semiestruturada, e os achados submetidos à análise temática, com o auxílio do software Atlas.ti. A pesquisa seguiu todos os cuidados éticos. Os resultados foram organizados em duas categorias analíticas: satisfação e insatisfação no trabalho. Condições de trabalho, relações no trabalho e percepções sobre o modo de trabalhar foram temas articuladores presentes nas duas categorias, revelando a dialética desses aspectos e indicando que condições objetivas e a forma como os trabalhadores lidam com elas influenciam o desfecho. Hospital como espaço de formação e trabalho foi relacionado unicamente com a satisfação, sinalizando um caminho promissor para gestores hospitalares e professores. Evidenciou-se a necessidade de investir nas condições de trabalho, organizar democraticamente os processos de trabalho e fomentar boas relações de trabalho. Os achados sinalizam um nicho de investigação importante e abrangente, com vistas a contribuir para formulação de políticas públicas e para a orientação de intervenções nos hospitais universitários.
\end{abstract}

PALAVRAS-CHAVE Saúde do trabalhador. Satisfação no emprego. Hospitais universitários. Pessoal de

1 Universidade de Brasília (UnB) - Brasília (DF),

Brasil.

magscherer@hotmail.com

2 Conservatoire National des Arts et Mètiers (CNAM) - Paris, França.

3 Universidade do Extremo Sul Catarinense (Unesc) Criciúma (SC), Brasil.

4 Universidade do Estado de Santa Catarina (Udesc) - Florianópolis (SC), Brasil.

5 Universidade Comunitária da Região de Chapecó (Unochapecó) - Chapecó (SC), Brasil.

6 Universidade Federal de Santa Catarina (UFSC) -

Florianópolis (SC), Brasil. saúde. Condições de trabalho.

ABSTRACT Descriptive study with a qualitative approach aiming to identify aspects that generate satisfaction and dissatisfaction in the work of health professionals at a university hospital. Study with 52 professionals from the surgical clinic and the emergency service. Data collection was carried out through semi-structured individual interviews, and the findings were submitted to thematic analysis with the aid of the Atlas.ti software. The research followed all ethical precautions. The results were organized into two analytical categories, job satisfaction and dissatisfaction. Working conditions, relationships at work and perceptions about the way of working were themes present in both categories, revealing the dialectic of these aspects and indicating that objective conditions and the way workers deal with them influence the outcome. The Hospital as a space for training and work was related solely to satisfaction, signaling a promising path for hospital managers and teachers. The need to invest in working conditions, democratically organize work processes and foster good working relationships was highlighted. The findings point to an important and comprehensive research niche, with a view to contributing to the formulation of public policies and for the guidance of interventions in university hospitals. 


\section{Introdução}

O processo de trabalho e o modo de organização nos serviços do Sistema Único Saúde (SUS), em especial, no cenário hospitalar, são temas debatidos na literatura atual, especialmente acerca do modo como esses aspectos interferem na saúde dos trabalhadores ${ }^{\mathbf{1 - 4}}$. Nesse contexto, os elementos que determinam a satisfação ou a insatisfação no trabalho são diversos, multifatoriais e dinâmicos, sofrem influência do ambiente, das condições de trabalho e da maneira ou capacidades do trabalhador para enfrentar as adversidades do meio ${ }^{5}$.

A satisfação e a insatisfação compõem um processo dinâmico, sendo que os trabalhadores podem estar satisfeitos com determinada situação e insatisfeitos com outros fatores ou condições. Aspectos como as relações interpessoais entre os indivíduos da equipe, condições de trabalho, organização dos serviços, divisão das tarefas, direitos trabalhistas, motivação e segurança podem influenciar a satisfação e a insatisfação dos profissionais ${ }^{2,6-8}$. $O$ trabalhador estar satisfeito ou insatisfeito gera consequências para a instituição, interferindo na produtividade, na qualidade do atendimento prestado aos usuários e no ambiente de trabalho, assim como na vida do trabalhador, com impactos em sua vida pessoal e familiar e no seu processo saúde-doença, ${ }^{6,7,9}$.

A insatisfação comumente está relacionada a vivências de inadaptação entre os componentes mental e físico, ao sofrimento, à ansiedade, às dificuldades na organização do trabalho, nem sempre explicitadas pelo trabalhador. Já a satisfação tem relação com o significado e o valor atribuído ao trabalho pelo indivíduo, com a capacidade de adaptação ao conteúdo das atividades produtivas, as relações interpessoais, a qualidade da tarefa prestada e o bem-estar ${ }^{10}$.

O trabalho em hospitais é influenciado pela introdução de inovações tecnológicas, por avanços no conhecimento científico e pela diversidade e complexidade das condições clínicas dos usuários. Trata-se de um ambiente onde predomina o modelo clínico de atenção, centrado nas especialidades médicas e no atendimento fragmentado aos usuários. Esse cenário é desafiante, tem implicações na saúde dos profissionais ${ }^{11-13}$, os quais precisam de educação permanente ${ }^{\mathbf{1 , 2}}$.

O ambiente de trabalho é um ambiente técnico, humano e cultural. E, como diz Schwartz ${ }^{14}$, marcado por todo tipo de infidelidades que se combinam, acumulam, reforçam-se umas nas outras, numa produção de variabilidades. Essas variabilidades precisam ser geridas pelos profissionais, produzindo processos de satisfação e insatisfação.

Diante do exposto, o presente estudo procura responder à seguinte questão de pesquisa: quais aspectos influenciam a satisfação e a insatisfação no trabalho de profissionais de saúde no cenário hospitalar?

\section{Material e métodos}

Trata-se de um estudo de abordagem qualitativa, do tipo descritivo, realizado em um hospital universitário no Brasil, no período de 2016 a 2017, com objetivo de identificar aspectos/elementos geradores de satisfação e insatisfação no trabalho de profissionais de saúde. O estudo desenvolveu-se nos serviços de Clínica Cirúrgica (CC) e de Emergência Adulto (EA). A escolha desses dois cenários assistenciais foi intencional, tendo em vista serem serviços comuns e prioritários nas instituições hospitalares, e, em geral, tipificam o trabalho nesses espaços assistenciais.

Participaram 52 profissionais, sendo 19 da CC (um assistente social, um fisioterapeuta, um nutricionista, dois médicos, três auxiliares de enfermagem, cinco enfermeiros e seis técnicos de enfermagem) e 33 da EA (um auxiliar de enfermagem, um assistente social, um nutricionista, quatro médicos, 11 enfermeiros e 15 técnicos de enfermagem).

Nos dois serviços estudados, há trabalhadores com contratos distintos de trabalho: os servidores públicos, com regime jurídico único, e os celetistas, vinculados à Empresa 
Brasileira de Serviços Hospitalares (EBSERH), implantada no hospital em 2013, com contrato regido pela CLT (Consolidação das Leis do Trabalho). Dos entrevistados, 38 eram celetistas, que ingressaram no hospital a partir de 2014, e 14 eram servidores públicos, sendo cinco com ingresso na década de 1990 e os demais de 2000 a 2006.

O critério de inclusão dos participantes foi ser profissional que presta assistência direta ao paciente, considerando os seguintes parâmetros: entrevistar ao menos um representante de cada categoria profissional e que atuasse em cada um dos três turnos de trabalho (matutino, vespertino, noturno). O número de participantes foi considerado suficiente pelo critério de saturação dos dados adotado em pesquisas qualitativas ${ }^{15}$.

Os dados foram coletados por meio de entrevistas orientadas por roteiro com perguntas abertas relacionadas ao trabalho dos profissionais em hospital universitário. O referido roteiro incluiu duas questões analisadas neste manuscrito: aspectos/elementos geradores de satisfação e de insatisfação no trabalho no referido contexto.

A análise dos dados foi orientada pela Análise Temática seguindo as fases de pré-análise, exploração do material e tratamento e interpretação dos resultados, associando-se recursos do software Atlas.ti para a organização e tratamento dos dados ${ }^{16,17}$. Após a transcrição das entrevistas, digitação em documento de texto, refinamento gramatical e ortográfico, os arquivos.doc [documents] foram inseridos no software Altas.ti. Nos documentos inseridos, foram selecionados os trechos de falas dos participantes [quotations], os quais foram tipificados por meio de códigos [codes] compostos por palavras que descrevessem a síntese da seleção. Por fim, os codes foram agrupados [codes groups] de acordo com seu conteúdo em quatro categorias temáticas que contemplam aspectos do trabalho que influenciam a satisfação e a insatisfação dos profissionais.
Com vistas a propiciar uma melhor visualização da magnitude dos aspectos geradores de satisfação e insatisfação no trabalho, os resultados da análise qualitativa foram apresentados, associando-se, de modo descritivo, as frequências absolutas (n) e relativas (\%) dos achados, considerando-se o total de trechos codificados relacionados a cada code, por categoria analítica: elementos/fatores geradores de satisfação e insatisfação no trabalho de profissionais de saúde de hospitais universitários. O tratamento e a interpretação dos resultados foram orientados pelos referenciais do Processo de Trabalho ${ }^{18}$, da Ergologia ${ }^{19}$ e da Psicodinâmica do Trabalho ${ }^{10}$.

O estudo respeitou todos os preceitos éticos para pesquisa com seres humanos, tendo sido aprovado em Comitê de Ética em Pesquisa da Faculdade de Ciências da Saúde da Universidade de Brasília sob parecer número 562.224/2014. Para a realização das entrevistas, foi garantido aos participantes um ambiente que oportunizasse sigilo. Nos resultados, para preservar o anonimato, não foram identificadas as profissões nem os locais de trabalho. As entrevistas foram codificadas pela letra ' $\mathrm{E}$ ' (entrevistado), seguida da letra 'C', quando o contrato de trabalho era regido pela CLT, ou 'S', quando o participante era servidor público, sendo posteriormente numeradas na ordem sequencial em que foram realizadas, por exemplo, EC1, ES2, e assim sucessivamente.

\section{Resultados}

A análise dos dados mostrou que, majoritariamente, os aspectos presentes no processo de trabalho dos profissionais de saúde têm um caráter dialético, gerando satisfação ou insatisfação, dependendo das condições que se apresentam e da forma como os trabalhadores lidam com eles. A figura 1 mostra a síntese da organização dos achados que compõem as duas macrocategorias analíticas e os quatro temas. 
Figura 1. Categorias temáticas que agrupam elementos geradores de satisfação e insatisfação no trabalho de profissionais de saúde de um hospital universitário no Brasil

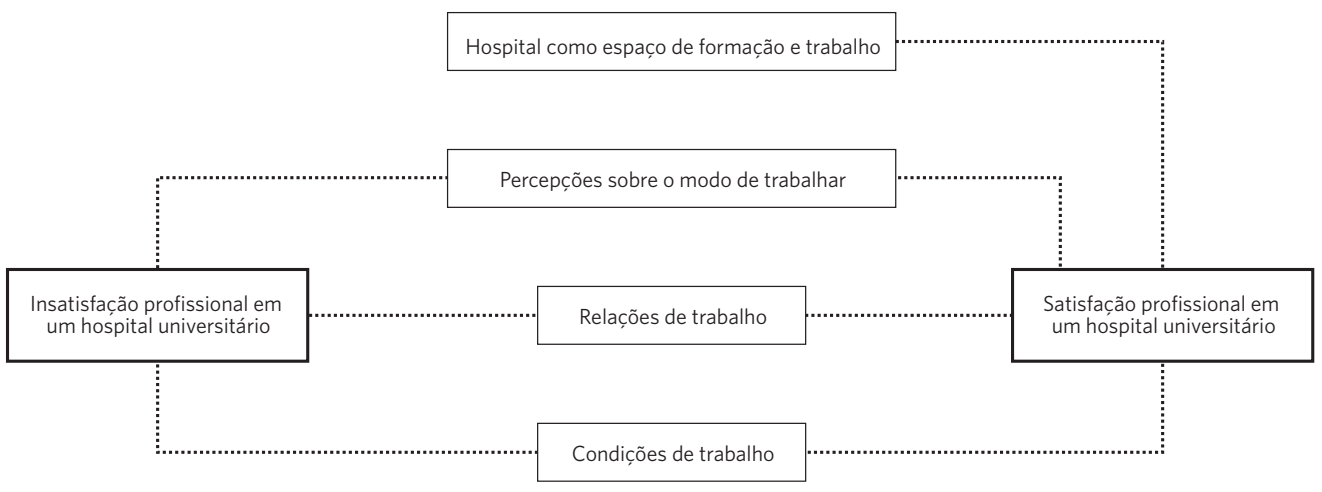

Fonte: Elaboração própria.

As sínteses dos achados relativos à satisfação e à insatisfação no trabalho dos profissionais de saúde do hospital estudado estão apresentadas nas tabelas 1 e 2, com as categorias temáticas associadas, além da descrição das respectivas magnitudes.
A 'satisfação profissional em um hospital universitário’ agregou 338 trechos (quotations), vinculados a 19 códigos, os quais foram articulados a quatro categorias temáticas, conforme a tabela 1.

Tabela 1. Categorias temáticas e códigos de acordo com o número e percentual de quotations relacionadas à satisfação dos profissionais de saúde de um hospital universitário no Brasil ( $n=338)$

\begin{tabular}{|c|c|c|c|}
\hline \multirow[b]{2}{*}{ Categorias temáticas } & \multirow[b]{2}{*}{ Códigos } & \multicolumn{2}{|c|}{ Quotations } \\
\hline & & $\mathbf{n}$ & $\%$ \\
\hline \multicolumn{4}{|c|}{ Hospital como espaço de formação e trabalho $(n=31-9,2 \%)^{\star}$} \\
\hline & Trabalhar em um hospital universitário & 17 & 54,9 \\
\hline & Aprendizado & 9 & 29,0 \\
\hline & Capacitação & 5 & 16,1 \\
\hline \multicolumn{4}{|c|}{ Condições de trabalho $(n=63-18,6 \%)^{\star}$} \\
\hline & Remuneração & 17 & 27,0 \\
\hline & Estrutura e ambiente de trabalho & 16 & 25,4 \\
\hline & Disponibilidade de instrumentos de trabalho & 14 & 22,2 \\
\hline & Administração da EBSERH & 5 & 7,9 \\
\hline & Jornada de trabalho & 5 & 7,9 \\
\hline & Direitos trabalhistas & 3 & 4,8 \\
\hline & Pessoal disponível para assistência & 3 & 4,8 \\
\hline \multicolumn{4}{|c|}{ Relações no trabalho $(n=186-55 \%)^{\star}$} \\
\hline & Trabalho em equipe e relação entre os profissionais & 81 & 43,5 \\
\hline & Relação com os pacientes & 38 & 20,4 \\
\hline & Apoio da chefia & 37 & 19,9 \\
\hline
\end{tabular}


Tabela 1. (cont.)

\begin{tabular}{|c|c|c|c|}
\hline \multirow[b]{2}{*}{ Categorias temáticas } & \multirow[b]{2}{*}{ Códigos } & \multicolumn{2}{|c|}{ Quotations } \\
\hline & & n & $\%$ \\
\hline & Relação com os outros setores & 26 & 14,0 \\
\hline & Comunicação & 4 & 2,2 \\
\hline \multicolumn{4}{|c|}{ Percepções sobre o modo de trabalhar $(n=58-17,2 \%)^{*}$} \\
\hline & Trabalhar com o que gosta & 23 & 39,7 \\
\hline & Assistência de qualidade & 23 & 39,7 \\
\hline & Resolubilidade da assistência & 7 & 12,1 \\
\hline & Reconhecimento e valorização profissional & 5 & 8,6 \\
\hline
\end{tabular}

Fonte: Elaboração própria.

*Subtotal e percentual referente à magnitude da categoria temática.

Por sua vez, a 'insatisfação profissional em um hospital universitário' contemplou um total de 352 trechos (quotations), vinculados a 24 códigos, os quais foram articulados a três categorias temáticas, conforme tabela 2 .

Tabela 2. Categorias temáticas e códigos de acordo com o número e percentual de quotations relacionadas à insatisfação dos profissionais de saúde de um hospital universitário no Brasil $(n=352)$

Quotations

\begin{tabular}{|c|c|c|c|}
\hline Categorias temáticas & Códigos & $\mathrm{n}$ & $\%$ \\
\hline \multicolumn{4}{|c|}{ Condições de trabalho $(n=234-66,5 \%)^{\star}$} \\
\hline & Deficit nos Instrumentos de trabalho & 46 & 19,7 \\
\hline & Estrutura & 28 & 12,0 \\
\hline & Burocratização do trabalho & 25 & 10,7 \\
\hline & Pessoal disponível para assistência & 24 & 10,3 \\
\hline & Escala & 22 & 9,4 \\
\hline & Administração da EBSERH & 21 & 9,0 \\
\hline & Remuneração & 18 & 7,7 \\
\hline & Capacitação & 14 & 6,0 \\
\hline & Jornada de trabalho & 12 & 5,1 \\
\hline & Excesso de trabalho & 12 & 5,1 \\
\hline & Vínculo & 7 & 3,0 \\
\hline & Distância de casa ao trabalho & 5 & 2,1 \\
\hline \multicolumn{4}{|c|}{ Relações no trabalho $(n=62-17,6 \%)^{*}$} \\
\hline & Relação com os outros setores & 17 & 27,4 \\
\hline & Falta de apoio da chefia & 15 & 24,2 \\
\hline & Trabalho em equipe e relação entre os profissionais & 14 & 22,6 \\
\hline & Comunicação & 11 & 17,7 \\
\hline & Relação com os pacientes & 5 & 8,1 \\
\hline
\end{tabular}


Tabela 2. (cont.)

\begin{tabular}{|c|c|c|c|}
\hline \multirow[b]{2}{*}{ Categorias temáticas } & \multirow[b]{2}{*}{ Códigos } & \multicolumn{2}{|c|}{ Quotations } \\
\hline & & $\mathbf{n}$ & $\%$ \\
\hline \multicolumn{4}{|c|}{ Percepções sobre o modo de trabalhar $(n=56-15,9 \%)^{\star}$} \\
\hline & Falta de compromisso profissional & 19 & 33,9 \\
\hline & Influência do trabalho na saúde & 15 & 26,8 \\
\hline & Desorganização dos profissionais com o trabalho & 8 & 14,3 \\
\hline & Falta de reconhecimento da chefia & 7 & 12,5 \\
\hline & Biossegurança & 4 & 7,1 \\
\hline & Falta de leito ou vaga & 3 & 5,4 \\
\hline
\end{tabular}

Fonte: Elaboração própria.

*Subtotal e percentual referente à magnitude da categoria temática.

A seguir, foram destacados trechos das entrevistas que evidenciam o conteúdo das categorias temáticas, demonstrando, com exceção da primeira categoria, a relação dialética presente nas falas dos participantes com relação a geração de satisfação e de insatisfação no trabalho.

\section{O hospital como espaço de formação e trabalho}

Trabalhar em um hospital universitário proporciona aprendizagem, o que foi considerado motivo de satisfação para os profissionais. Soma-se a isso, conforme os participantes, o fato de haver número menor de pacientes em relação a outros hospitais, por ser um hospital-escola, o que possibilita determinar uma rotina e construir um bom ambiente de trabalho. Além disso, destacaram a característica de ser um hospital de referência na rede de serviços e a relação pedagógica com residentes e estudantes da graduação, que oportuniza troca de experiências, torna o trabalho desafiador e exige busca contínua de conhecimentos.

Conforme os trechos:

O fato de ser um hospital-escola é um pouco mais fechado, não tem aquele tumulto de gente, você tem número delimitado de pacientes. Isso facilita bastante, dá para determinar uma rotina para atender. (ES28).
A relação com os estagiários e os residentes me dá muita satisfação porque é um aprendizado contínuo, a busca por conhecimento, o incentivo à pesquisa científica. Estar em um hospital universitário acabou sendo muito desafiador e muito gratificante. (ES35).

Essa categoria temática foi a única relacionada apenas à satisfação no trabalho.

\section{Condições de trabalho}

A adesão do hospital à EBSERH provocou mudanças na modalidade de emprego, gerando satisfação para alguns e insatisfação para outros.

Os que estavam satisfeitos relataram que a empresa valoriza os trabalhadores, que a gerência e a assistência melhoraram, que ocorreram reformas na estrutura. Além disso, que pontos eletrônicos foram instalados, melhorando o compromisso dos profissionais com o horário de trabalho. Os salários passaram a ser pagos em dia, e os vínculos temporários foram extintos. Destacaram-se nessa percepção profissionais que mudaram de um vínculo precário para a modalidade CLT.

Quanto à EBSERH, estou aqui desde quando era sem EBSERH. Totalmente diferente. Gerência diferente. Hoje funciona pelo ponto eletrônico, a filosofia de trabalho mudou. O funcionário da 
EBSERH é muito próximo do perfil do funcionário privado. Tem receio de ser punido, de ser mandado embora [...]. Essa mudança com a EBSERH foi drástica, em respeito ao público, ao funcionário. Vão cobrar [...] mas não é só cobrar, [dão] garantias, o salário em dia, não houve [...] perda salarial [...]. $\mathrm{Na}$ época que era contrato temporário, que tinha muitos, atrasava o salário três, quatro meses, era uma bagunça. Médico vinha trabalhar, ficava o tanto da carga horária que queria, enfermeiro, fisioterapeuta, qualquer profissional, não batiam o ponto e pronto. Isso vem mudando. Essa gerência da EBSERH mudou para melhor. (EC17).

Os profissionais insatisfeitos justificaram que a EBSERH é nova, sem identidade. Segundo eles, o hospital continua com problemas relacionados à falta de pessoal para assistência, ao acesso dos usuários ao hospital, pois este ficou mais burocrático, à redução do número de atendimentos e procedimentos. Consideram, também, que a diversidade de vínculos, direitos e deveres trabalhistas gera conflitos entre os profissionais.

Nós tivemos a passagem de gestão do hospital universitário para a EBSERH. O projeto trazia várias melhorias para a instituição hospitalar, 0 que na realidade não aconteceu. Primeiro, porque os concursos que ocorreram não atenderam às necessidades. $O$ que mudou foi a estratégia de modelo de gestão, com gastos maiores para fora e menos para dentro, para fortalecimento da instituição. Não precisava disso. Quem perde são os usuários dos serviços. (ES37).

A remuneração prevaleceu como fator de satisfação para os profissionais com contrato CLT, e de insatisfação para aqueles que são servidores públicos. Os satisfeitos com a remuneração justificaram que o salário sofre reajustes anuais, além de ser maior do que o de outros serviços e categorias profissionais. Conforme os trechos: "Me sinto confortável com o salário que recebo hoje, em relação a outras categorias de mesmo nível, em relação aos outros serviços por aî" (EC25).
O que faz a gente querer estudar para sair da empresa privada e querer ir para o serviço público é o salário. É sem comparação. Eu trabalhava numa empresa privada, eu recebia 900 reais, e vim para cá para receber quase quatro mil. [...] lá na Secretaria eu ganho metade do ganho aqui, mas como lá são vinte horas por semana, ainda compensa. O que vale a pena hoje em dia, minha fase é querer ficar num local, carga horária e $o$ salário. (EC33).

De acordo com os profissionais insatisfeitos, a remuneração dos servidores públicos está defasada, e, para os trabalhadores com vínculo celetista, a remuneração é maior. Segue trecho: "Estou insatisfeito com a questão salarial [...] eu recebo menos que os meus colegas que entraram nesse momento [quando o hospital aderiu à EBSERH]" (ES38).

A estrutura do hospital foi considerada um motivo de satisfação e insatisfação para os profissionais do serviço de EA. Os profissionais satisfeitos com a estrutura justificaram que boa parte do hospital foi reformada ou passa por reformas, possui espaço, com acessibilidade, e dispõe de materiais e equipamentos de qualidade. Conforme o relato:

É um local totalmente adaptado, tem banheiro adaptado, temos rampa. A altura das pias, dos balcões, todos são apropriados para um cadeirante utilizar, portas largas. (ES18).

Os profissionais que estavam insatisfeitos com a estrutura mencionaram que as reformas do hospital não foram bem planejadas, os responsáveis não ouviram a opinião dos trabalhadores, culminando em espaços físicos com diversas inadequações. Relataram que na EA existem alas muito pequenas, sem banheiro, sem copa, que em alguns espaços as equipes dividem os banheiros com usuários, potencializando o risco biológico para os trabalhadores.

Sobre o trabalho na CC, os profissionais relataram que os materiais foram armazenados só no terceiro andar, e sua entrega só pode ser feita por um profissional determinado. Os 
trabalhadores do segundo andar têm que se deslocar até o terceiro todas as vezes que precisam de material, o que consideram perigoso, pois, em caso de emergência com o paciente, o tempo para prestar assistência pode ser comprometido. E, ainda, as portas das alas reformadas não permitem a passagem das camas, que os locais de descanso existentes são insuficientes e concentram-se num andar, que as alas cirúrgicas são insuficientes, o que faz com que os pacientes demorem para ser operados.

O segundo andar é ala nova, reformada e não prevê sequer banheiro para os funcionários [...], a gente conta com um banheiro no final do corredor do terceiro andar, que é unissex. A gente está numa profissão que preza pela privacidade do paciente, pela intimidade, o sigilo, e a minha privacidade não está sendo respeitada [...]. Meu horário de trabalho são seis horas, mas, para chegar aqui, saio pelo menos meia hora antes e vou chegar em casa, pelo menos, meia hora depois, então são sete horas. Eu não posso ficar sete horas sem comer, uma reforma que não prevê o mínimo espaço para que eu possa fazer a minha refeição é desumano. (ES39).

De outro lado, a disponibilidade de materiais e equipamentos para o trabalho e a disponibilidade de espaço adequado de armazenamento, também foram motivos de satisfação. Entre os materiais mencionados estão os Equipamento de Proteção Individual (EPI), os insumos para realização de exames, as camas eletrônicas, os equipamentos de monitorização, ventilação e para exames de imagem do paciente.

Medicamento não falta para o paciente. Não falta insumos, luvas, EPI. Tudo a gente tem acesso aqui no Hospital. O paciente é monitorado, assistido, tem os equipamentos para poder facilitar a melhora dele. Questão de exames, se aqui não tem o aparelho que faça, se não tem o tipo de exame, é encaminhado para fora. (EC19).

O ambiente de trabalho do hospital tem sido fonte de satisfação por ser considerado sossegado, com espaço agradável. Conforme o trecho:
O ambiente bom de trabalho. O hospital está passando por uma interação nova com a EBSERH, então, assim, boa parte deles já está reformada. É bem interessante trabalhar aqui. (EC30).

Os profissionais insatisfeitos identificam deficits nos instrumentos de trabalho, em especial, a falta ou o sucateamento de materiais e equipamentos, como: ventilador, monitor, aparelhos para verificação de pressão arterial, para realização de eletrocardiograma e nebulização, oxímetro, equipamentos cirúrgicos, bomba de infusão. Faltam, também, fralda, seringa, capote, máscara, suporte de soro, poltronas, aparelho de barbear. Esses instrumentos de trabalho são essenciais na prestação da assistência, e deficits nessa área podem ocasionar riscos para profissionais e usuários, incluindo acidentes de trabalho, erros profissionais, infecções e diversos outros danos à saúde.

Material, duas semanas atrás, faltou bastante. Falta lâmina de barbear, materiais para a punção venosa, faltam coisas que facilitam a vida deles [paciente]. Eu não consigo ter fralda. Teve paciente meu que urinava na cama porque não tinha fralda e a família não tinha condições de comprar, tinha que ficar trocando a cama. São coisas que parecem básicas e são essenciais. Eu estava usando no lugar de fralda absorvente para paciente homem, só que não dá, porque a urina é muito maior que a quantidade do absorvente, a urina vazava muito. Na ora de evacuar, o absorvente não dava. Eu utilizava fralda de pano num senhor de 80 anos. [...] Elas meio que veem o nosso sofrimento e compram. (EC33).

A disponibilidade de pessoal para assistência por vezes é fonte de satisfação, por vezes de insatisfação no trabalho. Para os profissionais satisfeitos, o hospital não tem problemas com falta de pessoal para o trabalho. Segue trecho: "Ter recursos humanos suficientes é o que mais satisfaz, porque não tem nada pior do que você querer fazer e não ter como" (EC24).

No entanto, os profissionais insatisfeitos afirmaram que os setores têm falta de pessoal 
para assistência, com implicações na sobrecarga de trabalho. Há necessidade de remanejamentos nos setores para cobrir a carência de outros; e, no período noturno, os profissionais, muitas vezes, têm dificuldade de dispor do horário de repouso. Entre as categorias profissionais mencionadas como escassas para assistência, estão: técnicos de enfermagem, fisioterapeutas, nutricionistas, assistentes sociais e médicos.

Tem dias na Pediatria que fica uma enfermeira e duas técnicas. É muito trabalho para pouco funcionário. Acho que a EBSERH teria que ver isso. Ela fala que visa à qualidade do serviço, mas essa questão ela não visa. [...] Se lota o setor e não coloca funcionário suficiente. O que tem de funcionário de licença médica... A noite está deixando a desejar no número de técnicos. Porque à noite, querendo ou não, o funcionário tem direito à hora do repouso, do descanso [...]. (ES8).

Os profissionais satisfeitos relacionam, como aspectos que geram satisfação profissional, a escuta das necessidades do trabalhador pelo gestor, a flexibilidade no momento da formulação das escalas de trabalho e folgas. Conforme o trecho:

Sempre tem reuniões. Porque tem vários que trabalham em outros hospitais. O chefe sempre dá oportunidade de encaixar. Para não entrar em choque com escala do outro serviço. Eles sempre trabalham visando esse bem para o colaborador. (EC20).

Por outro lado, a falta de profissionais, ocasionando o remanejamento de trabalhadores entre os setores, foi motivo associado à insatisfação com a escala. Os participantes insatisfeitos alegam que são escalados em setores nos quais não têm perfil para trabalhar. Seguem exemplos:

Causa insatisfação é a escala, por esse problema de estar escalado em um lugar onde não tem perfil. (EC21).
Insatisfação é esse rodízio, que quebra a rotina. Porque hoje estou na medicação, amanhã na semi-intensiva, na sexta na pediatria. (EC6).

\section{Relações no trabalho}

No que diz respeito às relações no trabalho, foram incluídas aquelas que os profissionais estabelecem com outros setores do hospital, assim como no trabalho em equipe, as relações com os colegas, com a chefia e com os usuários dos serviços.

Quando mencionam aspectos de satisfação ou insatisfação com outros setores, referem-se, em geral, à farmácia, ao almoxarifado, ao laboratório, ao centro cirúrgico e ao transporte interno de pacientes. Por vezes, a relação é harmoniosa e fluída, quando as demandas são atendidas na temporalidade necessária, o que gera satisfação, mas, quando prevalecem as dificuldades de comunicação ou o que eles chamam de burocratização do trabalho, há insatisfação. De acordo com os profissionais, a burocracia está no excesso de papéis para registro, o que faz com que os pedidos aos setores muitas vezes demorem a ser efetivados, e, por sua vez, estes demorem a realizar determinados procedimentos, gerando conflitos entre os profissionais, além de influenciar a prestação da assistência ao paciente. Nesse contexto, muitas vezes, os medicamentos, exames, cirurgias, transferências de pacientes atrasam ou não são realizados. Conforme as falas:

A relação é bem tranquila. A farmácia consigo lidar bem, o Centro Cirúrgico também, eles me pedem paciente, eu tenho um tempo para arrumar para mandar. É boa a relação com os setores. (ES19).

Tem a demora, o laboratório, às vezes, a gente coleta, chama, e demora um pouco a vir. O maqueiro demora muito, isso é uma dificuldade, e grande, é um problema constante e recorrente. A farmácia demora um pouco, às vezes, tem um errinho de nada e eles ficam botando empecilho, dificuldade, sempre tem. São poucas as pessoas 
que têm a boa vontade de fazer no momento que $a$ gente pede. Eles perguntam, 'é urgência?'. Mas aqui é uma urgência, não precisa perguntar. Demora, a gente liga novamente, se estressa um pouco, chega até a brigar, 'ah, pedi o maqueiro há quase uma hora, o paciente tinha que fazer uma tomografia de urgência'. (EC3).

A colaboração e a coesão entre os membros da equipe se destacam como fontes de satisfação para a maioria dos participantes do estudo. Os profissionais insatisfeitos com o trabalho em equipe e com as relações com os colegas relataram que existem conflitos interpessoais, falta de interação e de iniciativa. Seguem exemplos:

Porque, assim, como é que a equipe [...] a gente nunca fica só. Sempre a gente recorre a alguém que já vivenciou. Se não vivenciou, a gente vai na luta para buscar. Mas... sempre a gente tem alguém para ajudar. (EC6).

Acho um desafio trabalhar em equipe, é o ideal, é fundamental, mas é um desafio. [...] O enfermeiro, o técnico de enfermagem com um tempo de formação, não tenho que ficar falando que o paciente está grave. Tem que olhar e ver. Realmente não tenho muita paciência. (ES16).

A equipe da noite, eu percebo que eles são bem coesos, eles são profissionais bastante capacitados, eles têm experiência. Os que não têm experiência a gente acolhe, a gente ajuda, orienta, fica junto e consegue, assim, desenvolver um bom trabalho, quando a gente puder... assim, está numa emergência máxima, todo mundo está ajudando, todo mundo se resolve, todo mundo colabora, a gente consegue ter o trabalho bom. Eu dou um... eu digo um trabalho bom a ótimo, porque a equipe... a equipe realmente se ajuda. (EC7).

Ainda no que tange às relações, os profissionais destacam a satisfação vinda do contato com os pacientes. Já a insatisfação deriva das cobranças que eles fazem e que não podem ser atendidas pelos profissionais. Como demonstram as falas:
Eu posso estar com o problema que eu estiver, mas quando eu entro no quarto do paciente, eu deixo os meus problemas. Dá até emoção, mesmo. Meu negócio são os pacientes. (EC52).

Tem paciente que pensa que está no hospital privado, que tem um técnico somente para aquela pessoa, tem de tudo aqui. É incrível. (EC51).

Também, o apoio da chefia sobressaiu como razão de satisfação para parte dos profissionais e de insatisfação para outros. A chefia acessível e presente traz satisfação, e aquela que se mostra restrita gera insatisfação. Conforme as falas:

A chefia aqui é bem acessivel. Você consegue sempre, se precisa ter acesso a eles, conversar e expor os seus problemas. Normalmente, sempre mensalmente tem reunião de setor. Ela abre para você colocar, expor todos os problemas. (EC23).

A nossa, do setor, não tem muita flexibilidade, não aceita muita opinião, às vezes, a gente fala que necessita de reuniões. Não é muito flexível, não escuta. Acho que se tivesse uma entre ela e a equipe, seria bem melhor. Falta comunicação. (EC26).

[A] chefia não está presente, às vezes que procuro, nunca consigo nada, não resolvo minhas coisas aqui. Tem uma diferença sim, de pessoas para pessoas, de tratamento. Tem pessoas que conseguem mudar escala, folga. Precisava ser uma pessoa mais proativa, mais presente. (EC31).

\section{Percepções sobre o modo de trabalhar}

Os profissionais percebem que trabalhar com o que gostam, prestar assistência de qualidade e ter seu trabalho reconhecido e valorizado promovem a satisfação. Segue exemplo:

Estou aqui para trabalhar e fazer o melhor, não importa a quem. O paciente merece uma resposta, seja 'sim' ou 'não', e eu vou atrás dela. Quando me 
chamaram no concurso, foi um dos dias mais felizes da minha vida. Não por ter o concurso, mas porque eu me formei em uma faculdade pública e, pela primeira vez, estou devolvendo para a população o que a população pagou para eu estudar. Não tem alegria maior para mim. Amo o que faço, faço por amor, sou apaixonada por enfermagem, não consigo me ver fazendo outra coisa. (EC40).

Cuidar do paciente se destaca como motivo de satisfação, uma vez que para parte dos participantes o processo assistencial é gratificante, bem como a resolutividade da assistência prestada. Conforme os trechos:

A minha maior satisfação é cuidar de um paciente e ver a reabilitação, a melhora dele, ir para casa, sair andando. Isso para mim é gratificante, gosto muito. (EC32).

Um senhor ficou aqui vários dias. A esposa dele, quando eu chegava: - ainda bem que você está aqui, me sinto confiante, sinto que as coisas vão dar certo. Isso pra mim é o melhor. (EC29).

Ao mesmo tempo, a falta de compromisso profissional de colegas e a influência do trabalho no seu próprio adoecimento são aspectos que geram insatisfação. Seguem trechos:

Acho que as pessoas são muito pouco proativas. Você pede um negócio, e a pessoa demora três anos para se levantar da cadeira. Isso me irrita profundamente. Não entende a gravidade. (ES16).

Tenho hérnia cervical com dor crônica, fibromialgia. Faço tratamento para depressão. (ES9).

Tenho asma, nosso repouso tem uma estrutura muito fechada, não consigo dormir lá, tem muito ácaro. Durmo no consultório. Botei dois anos um atestado porque tive pneumonia. O contato com os pacientes, as crianças e o repouso lá no ácaro. (EC10).

\section{Discussão}

Os resultados demonstram proximidade entre as macrocategorias satisfação e insatisfação, do ponto de vista da magnitude das quotations. E, ao analisar as categorias temáticas, observa-se forte influência das condições e relações de trabalho.

Estudos clássicos mostram que o trabalho humano pode ser fonte de realização, ao atender às necessidades e possibilitar a expressão criativa da finalidade projetada ${ }^{10,18}, \mathrm{e}$ pode ser gerador de insatisfação, dependendo das condições e relações de trabalho.

Neste estudo, as relações de trabalho emergiram como aspecto impulsionador da satisfação, com destaque para o trabalho em equipe, as relações entre os profissionais e destes com as chefias e os usuários, corroborando outros estudos ${ }^{\mathbf{1 3} 20}$. Contudo, em um sentido inverso, as relações se mostram insatisfatórias quando há problemas relacionais entre a equipe, com a chefia, com os usuários e com outros setores do hospital. A insatisfação quanto a esses aspectos poderia estar relacionada à percepção de que falta comprometimento de alguns colegas e às condições de trabalho no que tange à carência de pessoal nos setores e ao modo de organização do trabalho, considerado burocrático, com pouca margem de manobra na definição das escalas.

As condições de trabalho, sobretudo o deficit nos instrumentos, seguidas de problemas estruturais, que aparecem nesta pesquisa como elementos preponderantes para a insatisfação, são achados recorrentes também em diversos estudos ${ }^{11,13}$, e tendem a se impor como a questão central a dificultar o agir profissional. No entanto, outros aspectos não tão visíveis poderiam estar sendo mascarados, seja pelo fato de os participantes se colocarem em posição de exterioridade à situação em análise, por dificuldades de falar do seu trabalho ou por problemas na forma com que os dados são coletados nas diferentes pesquisas, que pouco acessam a complexidade da experiência no trabalho. 
Um projeto coletivo unindo as pessoas e contribuindo para dar sentido ao trabalho pode ser produtor de saúde dos trabalhadores. Lacunas de competências para lidar com o cotidiano dos serviços hospitalares poderiam estar na invisibilidade como aspectos de insatisfação. E o desenvolvimento de estratégias de enfrentamento das adversidades do meio poderia ser produtor de satisfação. Schwartz ${ }^{19}$ refere que o ser humano, para viver com saúde, gera as infidelidades do meio de maneira a transformá-lo.

Os resultados demonstram percepções distintas entre os participantes servidores públicos e aqueles com contrato regido pela CLT. Os primeiros tendem a ser mais críticos, manifestando insatisfação com a administração da EBSERH, enquanto os celetistas estão mais satisfeitos. É difícil fazer inferências quanto à influência da condição do emprego na satisfação ou insatisfação, considerando que $73 \%$ dos entrevistados são da EBSERH, e apenas $27 \%$ regidos pelo Regime Jurídico Único. No entanto, os achados evidenciam que o hospital universitário é, para os profissionais da EBSERH, em comparação ao hospital privado, um bom lugar para se trabalhar em função do salário, do ambiente e da carga horária. Já a satisfação com o fato de o hospital ser um espaço de formação e de aprendizagem destaca-se para os servidores públicos, possivelmente pela sua inserção mais antiga nos serviços estudados e pelo vínculo com o processo de ensino em serviço. Os novos não têm a história do hospital como patrimônio. Ao mesmo tempo, os dados sugerem algo comum entre eles: a defesa do serviço público como um valor.

A literatura tem registrado a complexidade da gestão hospitalar21, especialmente em um contexto de crescente diversificação dos tipos de vínculos trabalhistas nos serviços de saúde e educação ${ }^{22}$. Esses estudos, e outros, sinalizam a necessidade de acompanhar o crescimento da administração privada em hospitais públicos ${ }^{23}$. Associa-se a isso o aumento da potência de precarização dos vínculos frente à Reforma
Trabalhista recente e os problemas econômicos emergentes com a pandemia da Covid-19.

Os resultados sinalizam a importância de se efetivarem políticas de gestão do trabalho e de proteção dos trabalhadores, como a Política Nacional de Saúde do Trabalhador e Trabalhadora no SUS, buscando enfrentar desafios relacionados às ações de vigilância em saúde do trabalhador, à melhoria das condições e formas de organização do trabalho ${ }^{24}$.

No trabalho, fazer o que gosta e poder prestar um serviço de qualidade são percepções de satisfação identificadas no presente estudo que se assemelham ao encontrado na literatura ${ }^{1,9,25}$, especialmente pela oportunidade de cuidar/assistir as pessoas. Contudo, a percepção da falta de compromisso de alguns profissionais, que poderia estar associada à desmotivação para o trabalho, somada ao temor de adoecimento, parece reverter esse aspecto para o sentimento de insatisfação.

Nesse cenário, os potenciais prejuízos à convivência dos profissionais e à qualidade assistencial poderiam ser enfrentados na efetivação dos espaços democráticos de diálogo e tomada de decisão previstos em normativas nos hospitais universitários da rede EBSERH. Poderiam ser constituídos dispositivos de análise das situações de trabalho, onde todos os protagonistas, equipe assistencial, gestores e demais atores relacionados compartilhassem seus pontos de vista sobre o trabalho, buscando as transformações necessárias.

Compreender os fatores causadores de satisfação/insatisfação pode fornecer subsídios de aspectos propulsores de um trabalho permeado por relações com menor risco de adoecimento $^{13}$ e promotor de bem-estar no ambiente laboral.

\section{Considerações finais}

O conjunto dos achados evidencia que aspectos do trabalho no contexto assistencial hospitalar ocasionam vivências de satisfação e de insatisfação profissional, numa dualidade 
dialética. O que, possivelmente, também se relaciona com o lugar de onde cada trabalhador fala, marcado pela sua história, seus valores, experiências profissionais e relacionais, difíceis de medir e avaliar.

A análise revelou a prevalência de insatisfação dos profissionais com as condições de trabalho, demonstrando que, para melhorar a satisfação no contexto do hospital universitário, é preciso melhorar as condições de trabalho. Entre elas, disponibilizar materiais necessários para prestação da assistência, democratizar e organizar os processos de trabalho e fomentar boas relações entre os profissionais, possibilitando a construção coletiva no trabalho e a participação na gestão.

Alguns aspectos, como o gostar do que faz ou da profissão e realizar um trabalho que possibilita aprendizado constante, mostram-se positivos e podem ser objeto de investimento por parte dos gestores hospitalares e professores, com resultado benéfico para ambos, profissionais e pessoas cuidadas nos hospitais.

Como limites do estudo, cabe ponderar dois aspectos. Primeiro: o cenário restrito a um hospital público universitário. Reconhece-se que outros aspectos no debate da satisfação profissional em outros contextos hospitalares podem emergir, o que poderia ajudar a melhor elucidar alguns elementos aqui identificados. O segundo diz respeito ao desenho do estudo. Trata-se de estudo qualitativo, que na apresentação dos resultados opta pela explicitação da magnitude dos achados. Essa escolha pode ser vista como um limite, mas não se caracteriza como fuga epistemológica nem interferiu na atenção ao objetivo proposto.

Os achados sugerem novos estudos envolvendo hospitais, com olhar para o processo, as condições e relações de trabalho, em especial, para a contribuição dessa abordagem para a formulação de políticas públicas e para a orientação de intervenções em hospitais universitários.

\section{Colaboradores}

Scherer MDA (0000-0002-1465-7949)*, Soratto J (0000-0002-1339-7268)*, Trindade LL (0000-0002-7119-0230)* e Pires DEP (0000-0002-1754-0922)* contribuíram para concepção, planejamento, análise e interpretação dos dados; revisão crítica do conteúdo; e aprovação da versão final do manuscrito. Brito LM (0000-0001-7042-2549)* contribuiu para concepção, planejamento, análise e interpretação dos dados. 


\section{Referências}

1. Morais MP, Martins JT, Galdina MJQ, et al. Satisfação no Trabalho de Enfermeiros em um Hospital Universitário. Rev. Enf. UFSM. 2016; 6(1):1-9.

2. Farias DC, Araujo FO. Gestão hospitalar no Brasil: revisão da literatura visando ao aprimoramento das práticas administrativas em hospitais. Ciênc. Saúde Colet. 2017; 22(6):1895-1904.

3. Gaalan K, Kunaviktikul W, Akkadechanunt T, et al. Factors predicting quality of nursing care among nurses in tertiary care hospitals in Mongolia. Int. Nurs. Rev. 2019; 66(2):176-82.

4. Daneliu JL, Santos DVD, Stefanello S, et al. A percepção dos trabalhadores sobre o processo de trabalho em um Hospital Universitário Federal sob gestão de uma empresa estatal de direito privado. Saúde debate. $2019 ;$ 43(121):378-89.

5. Sartoreto IS. Satisfação e Insatisfação no Trabalho dos Enfermeiros: revisão integrativa da literatura. 2013. 2014 f. [dissertação]. São Paulo: Universidade de São Paulo; 2013.

6. Tambasco LP, Silva HS da, Pinheiro KM, et al. A satisfação no trabalho da equipe multiprofissional que atua na Atenção Primária à Saúde. Saúde debate. 2017; 41(esp):140-51.

7. Soratto J, Fernandes SC, Martinhs CF, et al. Aspectos geradores de satisfação e insatisfação dos profissionais da estratégia saúde da família de um município de pequeno porte da região sul do Brasil. Rev. CEFAC. 2018; 20(1):69-78.

8. Milanez TCM, Soratto J, Ferraz F, et al. Satisfação e insatisfação na Estratégia Saúde da Família: potencialidades a serem exploradas, fragilidades a serem dirimidas. Cad. Saúde Colet. 2018; 26(2):184-90.

9. Lima L, Pires DP, Forte ECN, et al. Satisfação e insatisfação no trabalho de profissionais de saúde da atenção básica. Esc. Anna Nery. 2014; 18(1):17-24.
10. Dejours C. A Loucura do Trabalho: estudo de psicopatologia do trabalho. São Paulo: Cortez; 2015.

11. Monteiro DT, Mendes JMR, Beck CLC. Health Professionals' Mental Health: A Look at their Suffering. Trends in Psyc. 2019; 27(4):993-1006.

12. Pinno C, Camponogara S, Beck CLC. A dramática do "uso de si" no trabalho da equipe de enfermagem em clínica cirúrgica. Texto Contexto Enferm. 2019; (28):e20170576.

13. Miorin JD, Camponogara S, Pinno C, et al. Prazer e sofrimento de trabalhadores de enfermagem de um pronto-socorro. Texto Contexto Enferm. 2018; 27(2):e2350015.

14. Schwartz Y, Durrive L. Trabalho \& Ergologia: conversas sobre a atividades humana. Niterói: Eduff; 2007.

15. Minayo MCS. Amostragem e Saturação em Pesquisa Qualitativa: consensos e controvérsias. Rev. Pesq. Qualitativa. 2019; 5(7):01-12.

16. Bardin L. Análise de conteúdo. Tradução Luís Antero Reto e Augusto Pinheiro. São Paulo: Edições 70; 2011.

17. Soratto J, Pires DEP, Friese S. Thematic content analysis using ATLAS.ti software: Potentialities for researchs in health. Rev Bras. Enferm. 2020; 73(3):e20190250.

18. Marx K. O Capital: crítica da economia política. Livro 1. 30. ed. Rio de Janeiro: Civilização Brasileira; 2012.

19. Schwartz Y. Le paradigme ergologique ou un métier de philosophe. Toulosse: Octares; 2000.

20. Pinhatti EDG, Vannuch MTO, Sardinha DSS, et al. Rodízio de Profissionais de Enfermagem entre Setores de um Hospital: Ferramenta Gerencial na Resolução de Conflitos. Texto Contexto Enferm. 2017; 26(2):el180015. 
21. Farias MR, Maciel JAC, Teixeira AKM, et al. O significado do trabalho para os profissionais de saúde da estratégia saúde da família. Rev. Psicologia Divers. Saúde. 2019; 8(2):167-78.

22. Galvão A, Castro B, Krein JD, et al. Reforma trabalhista: precarização do trabalho e os desafios para o sindicalismo. Cad. CRH. 2019; 32(86):253-70.

23. Reis MC, Coelho TCB. Publicização da gestão hospitalar no SUS: reemergência das Organizações Sociais de Saúde. Physis. 2018; 28(4):e280419.
24. Gomez CM, Vasconcellos LCF, Machado JMH. Saúde do trabalhador: aspectos históricos, avanços e desafios no Sistema Único de Saúde. Ciênc. Saúde Colet. 2018; 23(6):1963-70.

25. Morais MP, Martins JT, Robazzi MLCC, et al. Insatisfação no trabalho de enfermeiros de um hospital universitário. Cogitare Enf. 2014; 19(2):316-22.

Recebido em 28/11/2020

Aprovado em 28/07/2021

Conflito de interesses: inexistente

Suporte financeiro: Conselho Nacional de Desenvolvimento

Científico e Tecnológico (CNPq) Edital Universal 14/2013 